\title{
Salarios bajos, finanzas altas: contornos del debate marxista sobre la crisis capitalista global
}

\author{
David Thurston Martin \\ (traducción del inglés de Luis Rodolfo Morán Quiroz)
}

RESUMEN. Este ensayo examina cuatro libros publicados recientemente sobre la actual crisis capitalista desde la perspectiva de la economía política marxista. Estos libros resaltan los contornos emergentes del debate marxista sobre el origen y la naturaleza de la crisis capitalista actual. Las cuestiones planteadas en los libros son las siguientes: ¿la era neoliberal, desde 1970, representa un periodo de estancamiento o de expansión? ¿Lo que más contribuye a la crisis es el fracaso de la producción capitalista, el éxito de la financiarización o ambos? Aunque cada libro contribuye de manera importante al debate marxista, cada uno de ellos comete errores lógicos u omisiones empíricas. Afortunadamente, las debilidades de un libro son compensadas por los puntos fuertes de los demás, por lo que una lectura de conjunto proporciona una comprensión completa de la naturaleza dialéctica del desarrollo desigual del capitalismo global en la raíz estructural de la crisis.

PALABRAS CLAVE: economía política marxista, desarrollo desigual, financiarización, superproducción, tasa de ganancia.

Aвstract. This essay reviews four recently published books on the current global capitalist crisis from the perspective of Marxist political economy. These books highlight the emerging contours of the Marxist debate on the origins and nature of the current capitalist crisis. The issues raised by the books are as follows: did the neoliberal era, since the 1970s, represent a period of stagnation or expansion? What contributed more to the crisis: the failure of capitalist production, the success of financialization, or both? While each book makes significant contributions to the Marxist debate, they all make logical errors and/or empirical omissions. Fortunately, the weaknesses of one are compensated by the strengths of the others, so read together they provide a comprehensive understanding of the structural roots of the crisis, manifest in the dialectical nature of global capitalism's uneven development.

KEYWORDS: marxist political economy, uneven development, financialization, overproduction, profit rates.

David Thurston Martin es estudiante de la Unidad Académica de Estudios del Desarrollo de la Universidad Autónoma de Zacatecas. 


\section{INTRODUCCIÓN}

unque la controversia sobre las causas y las consecuencias de la
crisis capitalista global persistirá durante los años por venir, los
contornos del debate se han demarcado con la publicación de va-
rios libros que abordan las raíces estructurales de la crisis dentro de la tradición de la economía política marxista. En contraste con los académicos de la tradición neoclásica o keynesiana, estos autores enfatizan la naturaleza súper estructural de la crisis financiera y buscan las raíces estructurales en el ámbito de la producción. Los autores cuyas obras reseñamos aquí coinciden en que los años setenta marcaron un punto de inflexión en la historia del capitalismo, cuando entró en crisis la larga ola expansiva dibujada desde la segunda posguerra mundial. $\mathrm{Al}$ respecto existe consenso, pero las discrepancias afloran sobre si ese punto de inflexión se caracteriza por el estancamiento o expansión, por la sobreproducción o subconsumo, el aumento o descenso de las tasas de ganancia y de los salarios reales.

Por momentos, una parte del debate suena como si los generales discutiesen acerca de los sucesos de una batalla reciente, no de la presente batalla. $\mathrm{Al}$ respecto, William $\mathrm{K}$. Tabb hace la mayor aportación para abrir nuevos horizontes y explicar los nuevos instrumentos e instituciones financieros prevalecientes en la actual crisis, como derivados extrabursátiles, intercambio de deudas, fondos de inversión, firmas de capital privado y similares. Mientras que los temas debatidos por otros autores contribuyen a una comprensión de las causas subyacentes y del contexto de esta crisis, el enfoque de Tabb sobre el financiamiento ofrece el terreno más fructífero para la investigación y teorización futuras en la economía política marxista: ¿de qué manera el financiamiento afecta las leyes del capitalismo? 


\section{Foster y Magdoffः el abrazo simbiótico del ESTANCAMIENTO Y LA FINANCIARIZACIÓN}

En The Great Financial Crisis, John Bellamy Foster y Fred Magdoff reúnen una selección de ensayos de la revista Monthly Review, publicados entre 2006 y 2008, y añaden una introducción que sintetiza el argumento. El resultado es un poco repetitivo para los lectores de la revista; frecuentemente la argumentación se reitera en varios ensayos de la colección. Aunque repetitivo, no resta méritos al hecho de que los lectores ávidos de Monthly Review estaban muy conscientes de la probabilidad de la gran crisis financiera mucho antes que la mayoría de los observadores, lo que permitió a Foster y Magdoff publicar artículos sin revisar la publicación original. Pero más allá de reconocer los poderes predictivos de los autores, el libro ofrece una exposición clara y concisa del argumento de la escuela del «capital monopólico» establecida por Paul Sweezy, Paul Baran y Harry Magdoff, y fielmente impulsada por Foster y Magdoff (hijo de Harry).

Esta escuela argumenta que el capitalismo ha atravesado por etapas: capitalismo competitivo desde, aproximadamente, 1770 a 1870; capitalismo monopólico, de 1870 a 1970, y capitalismo monopólico financiero, de 1970 a la actualidad. Su argumento señala que a medida que madura el capitalismo tiende a estancarse y, por tanto, requiere cada vez mayores estímulos externos para impulsar el crecimiento. Esos estímulos externos pueden llegar en la forma de invención tecnológica, gasto militar, mercadeo y, finalmente, aunque de no menor importancia, finanzas especulativas y deuda. De tal modo, aunque la invención del automóvil estimuló un crecimiento enorme del capitalismo en el siglo $\mathrm{xx}$, la revolución de las tecnologías de la información y la comunicación (TIC) no ha logrado producir una transformación «de época» similar. En cambio, desde finales del gran crecimiento posterior a la guerra en los años setenta, las finanzas especulativas se han convertido en un «motor secundario para el crecimiento, dada la debilidad del motor primario, la inversión pro- 
ductiva» (Foster y Magdoff, 2009: 18). Es decir, la especulación financiera y la deuda constituyen los principales «estímulos externos» al elevar la demanda en la era del capital financiero monopólico.

La tendencia al estancamiento del capitalismo monopólico deriva de la sobreproducción o, como lo expresó Marx, «la verdadera barrera a la producción capitalista es el propio capital» (Foster y Magdoff, 2009: 20). Mientras que ampliaron la productividad y la capacidad productiva del capitalismo, el surgimiento de las corporaciones (primero nacionales y ahora transnacionales) generó el control monopólico de los mercados, donde las corporaciones se coludieron para mantener los precios altos y la producción baja. Esta tendencia generó ganancias enormes, al mismo tiempo que dejaba una gran capacidad productiva subutilizada. Desde los años setenta del siglo xx, el sector financiero ha absorbido buena parte del capital excedente, dirigiéndolo hacia una expansión basada en la deuda a medida que los sueldos reales se han estancado bajo el peso del estancamiento en la inversión productiva.

Foster y Magdoff argumentan que el ascenso de las finanzas desde fines de los años sesenta es «sintomático de la tendencia subyacente al estancamiento» del capitalismo monopólico, lo que ha derivado en un «abrazo simbiótico» entre el estancamiento y la financiarización (p. 20). Este periodo ha sido testigo de la "financiarización de la clase capitalista" en el sentido de una transformación en las fuentes primarias de acumulación de riqueza en la parte más alta de la sociedad, de la producción a las finanzas» (Foster y Holleman, 2010). Las finanzas «ascendieron» a invertir el capital excedente en formas más líquidas que la producción y generar ganancias especulativas bajo las condiciones de la crisis de sobreproducción.

El capital financiero desempeñó un papel cada vez más considerable para «resolver» el posterior problema de realización por medio de creación de deuda, la apertura de oportunidades de inversión a través de la especulación y la devaluación del capital por medio de la crisis financiera. Como consecuencia, el estancamiento, que comenzó a fines de los años sesenta, «puso las condiciones para un cambio considerable en el papel del sector financiero en el capitalismo 
estadounidense» (p. 18). Más que un «modesto ayudante» en el proceso de acumulación, las finanzas especulativas se convirtieron en «un motor secundario del crecimiento, dada la debilidad en el motor primario, la inversión productiva» (p. 18). Además, «la ampliación de la deuda y la especulación que caracterizó la economía estadounidense [...] desde fines de los años sesenta representó el principal medio a través del cual el sistema logró evitar hundirse en un profundo pozo, a la vez que no le permitió superar la subyacente tendencia al estancamiento» (p. 19). La ampliación del capital financiero de la deuda ayudó al capital productivo a realizar su producción sin aumentar los salarios; los trabajadores aumentaron su consumo por medio de niveles más altos de deuda, no de salarios. Raghuram Rajan, antiguo jefe de economistas en el Fondo Monetario Internacional (FMI), llamó a esta estrategia «déjenlos que coman crédito» (2010). Es decir, el capital «resolvió» el problema de la realización de la crisis de sobreproducción por medio de la explosión de la deuda del hogar mientras los sueldos reales se estancaron desde los años setenta.

Aunque estos «estímulos externos» de la ampliación de la deuda sirvieron como un motor secundario de crecimiento de cara al estancamiento subyacente, también crearon las condiciones de mayor volatilidad, ya que el crecimiento llegó a depender de las burbujas especulativas y sus caídas inevitables. Foster y Magdoff describen la dependencia del capital monopólico de las finanzas respecto al crecimiento impulsado por la deuda como un drogadicto que necesita cada vez mayores «arreglos» especulativosः «el sistema se tornó cada vez más dependiente de una serie de burbujas financieras para seguir funcionando, cada una de ellas más grande que la anterior» (p. 18). Esta necesidad de burbujas cada vez mayores para estimular el crecimiento explica el movimiento de la serie de burbujas (y crisis) financieras desde la periferia hacia el centro, es decir, desde la periferia de la crisis de la deuda del tercer mundo en 1982 al centro de la crisis de Wall Street en 2008. Sólo los mercados financieros tan «profundos» y «sofisticados», como los que se ubican en Wall Street, podrían generar una burbuja inmobiliaria de ocho billones de dólares en el centro de la gran crisis financiera (Baker, 2009). Dada la financiarización de la clase capitalista, la «solución» a 
la crisis emanada de la estructura de poder no ha sido la nacionalización de los bancos y su conversión a empresas públicas, sino más bien la intervención del Estado para rescatar a Wall Street con billones de dólares y, con ello, dejar que los adictos de Wall Street conduzcan la economía con la esperanza de que encuentre otra solución especulativa.

\section{UnA Crítica a Foster y Magdoff}

Primero, y sobre todo, la noción de que la innovación tecnológica, la guerra, el imperialismo, la mercadotecnia, la publicidad, la especulación financiera y la deuda doméstica son «estímulos externos» para la lógica interna del capitalismo ignora la historia del capitalismo, en la cual la innovación, la guerra, el imperialismo, el militarismo, el racismo, las burbujas especulativas, las crisis financieras y la deuda han desempeñado un papel central en la superación de la «verdadera barrera» del «propio capital» al destruir y devaluar al capital y al estimular violentamente nuevas oleadas de expansión capitalista. Esto es, con objeto de argumentar que a medida que madura el capitalismo se estanca, Foster y Magdoff excluyen categóricamente los procesos sociales que superan las barreras a la expansión capitalista como «estímulos externos». Para argumentar a favor de la tendencia al estancamiento del capitalismo monopólico, afirman que estos procesos sociales que alimentan el dinamismo del capitalismo son externos a su lógica. Desafortunadamente, no lo son.

Además, los datos utilizados por Foster y Magdoff para afirmar que el capitalismo se ha estancado en la era neoliberal provienen en su totalidad de Estados Unidos, excluyendo arbitrariamente la expansión del capitalismo en otras regiones. Están al menos conscientes de esta afirmación y argumentan que su enfoque centrado «casi exclusivamente en el desarrollo de la crisis financiera global dentro del contexto de la economía estadounidense» está justificado dado que «las principales contradicciones del capitalismo todavía se perciben mejor [...] desde el punto de vista de la principal economía capitalista en una 
etapa dada de su desarrollo» (Foster y Magdoff, 2009: 21). Pero, ¿̇es posible captar las principales contradicciones del capitalismo actual, dada su naturaleza global, al enfocar un solo país, incluso si éste constituye «la principal economía capitalista»? Este enfoque sobre el estancamiento convenientemente excluye la expansión histórica del capitalismo en China. Para argumentar que el capitalismo se ha estancado desde los años setenta, Foster y Magdoff se calan unas viseras localistas e ignoran, posiblemente, el surgimiento más dinámico del capitalismo en la historia mundial (Li, 2008). En otras palabras, de igual manera que clasifican a la innovación, la guerra, la especulación y la deuda como externos a la lógica del capitalismo, argumentan que el surgimiento de China, el taller del mundo, es externo a las principales contradicciones del capitalismo.

Desde una perspectiva global, en vez de una localista fijada en Estados Unidos, puede advertirse que el capitalismo se ha expandido no sólo en China, donde lo ha hecho más dinámicamente, sino también en Rusia y Europa del Este, al igual que en buena parte del resto del mundo. Esta expansión geográfica ha acelerado la acumulación primitiva, «un proceso en el cual millones han sido apartados de los medios de producción, se han proletarizado y han sido lanzado al mercado global de la fuerza de trabajo configurado por el capital transnacional» (Robinson, 2008: 25). Esta aceleración de la acumulación primitiva ha duplicado la fuerza de trabajo asalariada global de 1.46 en 1980 a 2.92 miles de millones en 2006 al «entrar en la reserva global de fuerza de trabajo los trabajadores de China, India y el antiguo bloque soviético» (Freeman, 2006: 1). Si duplicar la clase trabajadora en la era neoliberal es señal de estancamiento, ¿`ómo se vería la expansión?

\section{McNally; De la eXPANSión NeOliberal}

\section{AL DETERIORO GLOBAL}

En 2009, Sasha Lilley, editora de la serie Spectre de la editorial PM, entrevistó a David McNally en su programa de radio «El capitalismo y sus desgracias» 
acerca de la crisis capitalista global. La entrevista se volvió tan popular que Lilley estimuló a McNally a escribir un libro sobre ella. Afortunadamente, McNally aceptó el reto y escribió Global Slump: The Economics and Politics of Crisis and Resistance para públicos a la vez populares y académicos. De todos los libros que reseñamos aquí, McNally ofrece la perspectiva más global sobre la crisis actual. No es de sorprender, dado que su libro de 2002, Another World Is Possible: Globalization and Anti-Capitalism, examinaba el movimiento global a favor de la justicia desde, digamos, una perspectiva global, al analizar al movimiento no sólo en Norteamérica, sino también en América Latina, Asia, África y Europa. En Global Slump pone su ojo crítico desde la resistencia global desde abajo hacia la crisis global desde arriba.

McNally describe la actual crisis como un deterioro ( $\operatorname{lum} p)$ global, porque «el término pretende captar todo un periodo de crisis interrelacionadas - la explosión de la burbuja inmobiliaria, una oleada de colapsos bancarios, una serie de crisis de soberanía por la deuda, recaídas en la recesión- que se alarga durante años sin una recuperación económica sostenida» (pp. 8-9). Es decir, la crisis financiera que se desató en Wall Street no constituye una crisis aislada, sino «una mutante». Además, McNally está fuertemente en desacuerdo con académicos como Foster y Magdoff y Robert Brenner (2002) que caracterizan el periodo neoliberal como «estancamiento» o como «un largo descenso» (p. 36). En cambio, argumenta que el neoliberalismo arrancó de golpe un nuevo ciclo de crecimiento capitalista entre 1982 y 1997, produciendo un nuevo centro de acumulación de capital en Asia oriental, en especial en China. Según McNally, el neoliberalismo logró esta expansión, principalmente, mediante la intensificación de la explotación de la fuerza de trabajo en todo el mundo, al atacar a los sindicatos en el Norte global, debilitar a los Estados en desarrollo en el Sur global, globalizar la producción, ampliar el ejército de reserva de fuerza de trabajo global y reorganizar el trabajo con nuevas tecnologías (es decir, la revolución de las TIC). Aunque este proceso implicó «turbulencia global», estimuló la tasa de ganancia y una expansión capitalista sostenida $(p .41)$. 
Pero este ciclo neoliberal de crecimiento se terminó con la crisis financiera del este de Asia en 1997, marcando el «inicio de nuevos problemas de sobreacumulación» (p. 41). Estos problemas no se manifestaron como una crisis global generalizada en 1997, porque «la expansión del crédito durante toda una década retrasó el día del juicio», hasta que explotó la burbuja inmobiliaria en 2006-2007 (p.41). Esencialmente, McNally está en desacuerdo con Foster y Magdoff respecto a la periodización, cuando argumenta que el periodo neoliberal de 1982-1997 se caracteriza por la expansión, no por estancamiento; aunque después de 1997 la dinámica de estancamiento-financiarización entró en vigor. Bajo condiciones de sobrecapacidad en la economía global, una expansión de crédito infló las burbujas de valores y generó una explosión en la deuda de los hogares, lo que por medio del «efecto de riqueza» y el crédito al consumo generó una demanda efectiva, evitando una crisis de sobreproducción. En otras palabras, McNally no niega que la actual crisis global tenga raíces estructurales en la sobreproducción, el estancamiento y la financiarización, mas afirma que esas raíces se remontan a 1997 y no a los años setenta.

\section{Una CRítica de McNally}

Desde una perspectiva global, la definición de McNally del deterioro global como una serie de crisis interrelacionadas, desde, por ejemplo, las crisis financieras hasta las crisis de las deudas que cuestionan la soberanía, no sólo se aplica al periodo que se inicia en 2007, sino a todo el periodo neoliberal a partir de los años setenta. Como lo expresara David Harvey, «el capitalismo nunca resuelve sus problemas de crisis, sólo los mueve de un lugar a otro» (Harvey, 2010). Este desplazamiento de la crisis de sobreproducción, generado por la recuperación del capital europeo y japonés, desde la destrucción de la segunda guerra mundial hacia las finanzas globales, ha creado una serie de crisis financieras interrelacionadas, una vorágine de burbujas y caídas, desde la «crisis petrolera» de los años setenta. 
$\mathrm{Al}$ argumentar que el inicio de los problemas de sobreacumulación comenzó en 1997, y no en los años setenta, y que la ampliación del crédito evitó una crisis «general» en el periodo de 1997 a 2007, y no antes, desafortunadamente McNally demuestra la misma perspectiva localista frente a la cual argumenta enérgicamente cuando, por ejemplo, afirma que «los principales países capitalistas están lejos de encarnar toda la historia de la economía global de nuestra época», o que la economía mundial es «más que la suma de sus partes más grandes», como Estados Unidos, Alemania y Japón (p. 37). Pero luego no considera una crisis como «general» sino hasta que se centra en los países capitalistas centrales, y específicamente en Wall Street, con la explosión de la burbuja de las empresas punto-com en 2000 y la burbuja inmobiliaria en 2007. Pero desde la perspectiva de la economía mundial, el periodo neoliberal constituyó una crisis general o, más precisamente, una serie de crisis interrelacionadas.

McNally ubica los orígenes de la financiarización en la decisión de $\mathrm{Ri}$ chard Nixon de «cerrar la ventanilla del oro» en 1971, dando fin al acuerdo de Bretton Woods que había garantizado que el dólar podría ser convertido en oro a 35 dólares la onza. Argumenta que el consecuente «no sistema flotante» de las tasas de cambio generó una explosión de instrumentos financieros de cobertura limitada y otros más, a medida que las corporaciones multinacionales buscaban maneras de reducir la exposición a la volatilidad de las tasas de cambio de divisas. Pero aquí McNally confunde causa y efecto, o sobreproducción y financiarización. El fin de Bretton Woods y las tasas flotantes de intercambio surgieron de las presiones estructurales de una crisis de sobreproducción, no de financiarización.

Con el fin de la segunda guerra mundial, los intereses empresariales de Estados Unidos temieron el retorno de la Gran Depresión y, para estimular la demanda, apoyaron la reconstrucción de Europa, y luego de Japón, para generar mercados que absorbieran sus excedentes. Esto significó bombear dólares a estas economías de modo que pudieran comprar bienes manufacturados en Estados Unidos. Pero a medida que los europeos y los japoneses se recuperaban y comenzaron a competir con las exportaciones estadounidenses 
en el mercado mundial, la economía mundial entró en una crisis de sobreproducción (Brenner, 2002). Para competir con sus nuevos rivales, las industrias estadounidenses necesitaban optar por imponer una devaluación interna (es decir, reducir los costos de mano de obra) o por devaluar el dólar cerrando la ventanilla del oro. Dado el poder de la fuerza de trabajo estadounidense y de los movimientos sociales de los años sesenta, se optó por esto último.

La clase capitalista estadounidense estaba interesada en debilitar el poder de la fuerza de trabajo, pero, en ese momento, habría que posponer un «ataque frontal» a la fuerza de trabajo hasta que ésta se debilitara a través de una estrategia de «estanflación» (Arrighi, 2007: 130). Según Giovanni Arrighi, en su último libro publicado antes de morir, Adam Smith in Beijing: Lineages of the Twenty-First Century, señala que:

[...] al final del largo periodo ascendente de la posguerra, la influencia de la fuerza de trabajo era suficiente para que cualquier intento de hacerla retroceder por medio de una deflación resultara demasiado riesgoso en términos sociales y políticos [...] Una estrategia inflacionaria [...] prometía debilitar el poder de los trabajadores de manera mucho más efectiva. Fue, en efecto, el gran estancamiento - en cuanto inflación de los setenta- «estanflación», [...] la que efectivamente acabó con el poder de los trabajadores (Arrighi, 130).

La estanflación de los años setenta, especialmente la relacionada con el reciclaje de los petrodólares y la crisis de la deuda del tercer mundo, capta la interrelación de las crisis surgidas de la crisis de sobreproducción, a partir de fines de la década de los sesenta.

Con el objetivo de conservar al dólar como la divisa de las reservas mundiales, tras el cierre de la ventilla del oro, el régimen de Nixon procedió a establecer un trato secreto con la monarquía saudita y con el Shah de Irán para elevar el precio del petróleo, que sólo es comercializado en dólares (Gowan, 1999). Según John Perkins, en The Secret History of the American Empire, la 
«corporatocracia» estadounidense desempeñó un «papel activo en impulsar los precios del petróleo a estas alturas sin precedente. Aunque los líderes empresariales y políticos, incluidos los ejecutivos petroleros, fingían indignación, eran ellos los titiriteros que jalaban los hilos» (Perkins, 2008: 171). Dado que el comercio petrolero se realizaba únicamente en dólares, el alto precio del petróleo obligó a los bancos centrales a tener más dólares en reserva, derivando en la sustitución del estándar dólar-oro por un estándar dólar-petróleo que fortaleció la «hegemonía del dólar» (Perkins, 2007: 171).

Este trato secreto para elevar el precio del petróleo también incluía un acuerdo para reciclar el excedente de los petrodólares, o de las ganancias del petróleo, hacia los bancos estadounidenses, en lo que Perkins denominó «el asunto del lavado de dinero en Arabia saudita» (2007: 172). Como consecuencia, los bancos estadounidenses contaban con capital excedente para invertir pero, en el contexto de la crisis de sobreproducción, tenían pocos lugares para invertir en una producción ampliada. En cambio, voltearon hacia los gobiernos del tercer mundo y promovieron con ellos los préstamos con tasas flexibles. Según Arthur MacEwan, en Debt and Disorder: International Economic Instability and us Imperial Decline, la sobreproducción en el centro capitalista implicó que «en los países capitalistas avanzados, la demanda de crédito no siguió el paso de la floreciente oferta de fondos. Enfrentados con una rápida ampliación de la liquidez que no podía ser absorbida en el centro, los bancos comenzaron a promover que llegaran los fondos a la periferia del capitalismo mundial» (MacEwan, 1991: 61). Dado que los petrodólares no se invertían en la producción en Estados Unidos, sino que eran reciclados hacia los gobiernos del tercer mundo, la consecuencia fue un crecimiento más lento en el empleo y un mayor desempleo, generando una inmensa presión sobre los sindicatos estadounidenses. Los mayores precios del petróleo en 1970 desataron también la inflación, lo que debilitó los sueldos sindicalizados, dado que sus contratos no lograban llevarle el ritmo a los precios que se elevaban. Quedó listo el escenario para un ataque frontal.

Ese ataque se dio bajo la forma de un marcado incremento en las tasas de interés en Estados Unidos, lo que no sólo impactó a la economía con un 
alto desempleo sino que quebrantó el poder de la fuerza de trabajo, y además llevó a la quiebra a muchos gobiernos del tercer mundo al provocar una crisis de la deuda soberana. Estos gobiernos vieron cómo se disparaban sus pagos de servicio de la deuda generada por los préstamos a tasa de interés flexible que habían recibido de los bancos de Estados Unidos durante el reciclaje de los petrodólares, así cómo sus mercados de exportación se derrumbaban debido a la recesión. Al igual que la actual oleada de crisis de deuda soberana se utiliza para imponer la austeridad, la crisis de la deuda del tercer mundo ha servido como mecanismo para imponer la reestructuración neoliberal, especialmente por medio de los programas de ajuste estructural (PAE) del FMI.

Llamar «expansión neoliberal» a la imposición de austeridad en el tercer mundo a través de los PAE, representa una caracterización inadecuada de un proceso cuyo fundamento se encuentra en la destrucción del capital del tercer mundo y la consecuente resubordinación al Norte global. Al atribuir el aumento de la financiarización a la volatilidad de los tipos de cambio tras el cierre de la ventanilla del oro, McNally ignora el desplazamiento de la sobreproducción hacia el tercer mundo por medio de los PAE. En cambio, McNally se centra estrechamente en el surgimiento de unos cuantos centros de acumulación en el este de Asia para justificar el término «expansión», cuando en el contexto global buena parte del tercer mundo estaba experimentando desacumulación. Al diagnosticar erróneamente la causa de la crisis en el periodo 1973-1982, McNally puede afirmar luego que el neoliberalismo «curó» la crisis, restauró la rentabilidad y generó las condiciones para una expansión en el periodo 19821997. Pero si el neoliberalismo trasladó la crisis al tercer mundo, por medio de la crisis de la deuda y reestructuró las relaciones laborales en el Norte global, entonces la crisis estaba lejos de terminar, estaba mutando.

De hecho, la crisis de la deuda del tercer mundo no constituía una señal del fin de la volatilidad de los años setenta, sino que, en cambio, iniciaba una serie de crisis financieras que marcaron el periodo neoliberal hasta el momento. Por nombrar sólo algunas: la caída de la bolsa de valores en 1987, la crisis de ahorros y préstamos de fines de los ochenta en Estados Unidos, la crisis de 
la libra esterlina en 1992, la crisis del peso mexicano en 1994, la crisis financiera del este de Asia en 1997 (principalmente Indonesia, Tailandia, Corea del Sur y Filipinas), la crisis de largo plazo de la gestión del capital en Brasil y Rusia en 1998, la crisis de las empresas punto-com, la crisis argentina en 2001 y el continuado «deterioro global» desde 2007. La crisis financiera del este de Asia en 1997 no marcó un punto de inflexión en esta serie, sino una aceleración de la crisis. Estas crisis financieras están arraigadas en la crisis de sobreproducción, comenzada a fines de la década de los setenta, cuando el capital se trasladó a la búsqueda de ganancias especulativas (apostando al surgimiento o caída en el precio de un recurso) y la liquidez, promoviendo la liberalización financiera y la innovación. La consecuencia ha sido una serie de rápidos altibajos de burbujas y explosiones de activos. A lo largo del mismo periodo, la deuda (gubernamental, corporativa, del hogar) también ha explotado. De tal forma, en contra de lo que afirma McNally, el ascenso de las finanzas y la expansión del crédito comenzaron mucho antes de la crisis financiera del este de Asia en 1997 y ha continuado a un paso acelerado desde entonces. Es decir, la crisis financiera de 1997 no constituyó un punto de inflexión, sino un punto de datos en una tendencia hacia la financiarización.

Lo mismo podría decirse de China; la crisis financiera del este de Asia en 1997 nada hizo para detener su trayectoria de crecimiento. Argumentar que la expansión neoliberal terminó en 1997 y que esa expansión tiene su mejor ejemplo en el surgimiento de un nuevo centro de acumulación de capital en China, implica que la expansión china debió concluir en 1997. Lejos de ello, el crecimiento chino siguió con su ritmo de dos dígitos hasta hace poco (los informes recientes lo sitúan en $7 \%$, todavía más dinámico que cualquier otro centro de la economía capitalista). Si la afirmación de que la expansión neoliberal dependió de la creación de un nuevo centro de acumulación en China y la expansión china continúa, ¿̇eso significa que la expansión neoliberal continúa? Según McNally, la expansión terminó en 1997, pero la lógica de su argumento lleva a la conclusión de que continúa. Esta dificultad surge del estrecho enfoque de McNally sobre China para justificar la afirmación de una «expansión neoliberal». 
Mientras que, por un lado, McNally exageró la expansión del capitalismo en la época neoliberal al centrarse en el surgimiento dinámico de un nuevo centro de acumulación de capital en el este de Asia, en especial China, por el otro pierde de vista la generalizada desacumulación en el tercer mundo y la financiarización en Estados Unidos en el mismo periodo. Foster y Magdoff, por otra parte, exageraron el estancamiento del capitalismo en la época neoliberal, perdiendo de vista la expansión geográfica del capitalismo hacia los antiguos países comunistas y la duplicación de la fuerza de trabajo asalariada global. Esta aparente contradicción demuestra la naturaleza dialéctica del desarrollo desigual del capitalismo en la economía global y los peligros de centrarse en una región o país excluyendo a otros, especialmente con un capitalismo globalizado.

Además, la dialéctica del estancamiento y la expansión en la economía global da indicios de una transición hegemónica. Según Giovanni Arrighi: «si las tendencias del pasado sirven de guía para el presente y el futuro, podríamos esperar que la expansión financiera restaurara temporalmente las fortunas de la agencia capitalista líder de la época, Estados Unidos, pero eventualmente derivaría en el cambio de liderazgo en el centro de la acumulación de capital a escala mundial» hacia China (Arrighi, 2010: 371). Mientras que centrarse en el estancamiento de Estados Unidos o en la expansión en China deja de lado su relación dialéctica, del mismo modo sucede con enfocarse en la producción mientras se excluye a las finanzas o viceversa. Es decir, centrarse exclusivamente en la sobreproducción o en la financiarización, como Andrew Kliman y William $\mathrm{K}$. Tabb hacen en los siguientes dos libros reseñados, entraña el riesgo de perder de vista la relación dialéctica entre sobreproducción y financiarización.

\section{Kliman: LA TASA DE Ganancia EN DeClive}

Kliman adopta un enfoque similar al de Foster y Magdoff, desde el cual analiza datos de Estados Unidos para argumentar que la economía nunca se ha recuperado de la crisis de sobreproducción, comenzada en los años setenta. 
Argumenta que la ley de Marx de la tendencia decreciente de la tasa de ganancia ofrece la mejor explicación de la causa de la crisis financiera actual, que se ha convertido en una «gran recesión» debido a la debilidad subyacente de la economía. La tendencia a la reducción de la tasa de ganancia se deriva de la idea de Marx de que «la verdadera barrera a la producción capitalista es el capital mismo» (Foster y Magdoff, 2009: 20). A medida que se acumula el capital y aumenta la productividad, se necesita menos fuerza de trabajo para producir mercancías, pero esto debilita la tasa de ganancia dado que el trabajo vivo (frente al trabajo muerto de la maquinaria del capital) es la fuente última del valor excedente. La única forma de contrarrestar esta tendencia es a través de la destrucción del capital (ya sea financiera o físicamente) para reiniciar el proceso de acumulación y, en consecuencia, restaurar las altas tasas de ganancia.

Kliman argumenta que dado que la clase capitalista temía la precipitada caída en la tasa de ganancia y el retorno de la radicalización de la clase trabajadora de la Gran Depresión, los diseñadores de políticas han usado las intervenciones fiscales y monetarias para «evitar la destrucción plena del valor del capital» desde los años setenta (p. 3). Pero, según Kliman, es precisamente el que no se haya logrado destruir suficiente capital desde los setenta que las tasas de ganancia han decaído y la producción capitalista ha permanecido lenta. La falta de destrucción del capital ha generado la condición por la cual el empleo se ha incrementado demasiado lentamente en relación con el capital acumulado, derivando en una tasa de ganancia en declive. Kliman argumenta que mientras que él «no defiende la destrucción plena del capital», ello incrementaría, desde su perspectiva, la tasa de ganancia.

Kliman se enfrasca en una densa explicación técnica de cómo llegó a la conclusión de que las tasas de ganancia han caído persistentemente desde los años setenta, en contraste con McNally, quien afirmó que la reestructuración neoliberal restauró la rentabilidad desde 1982 hasta 1997. Básicamente, utiliza un enfoque del costo histórico más que la perspectiva del costo actual para las inversiones de valor fijo en el sector corporativo con el propósito de medir las ganancias. Además, argumenta que, lógicamente, si las tasas de ganancia 
eran altas durante el periodo neoliberal, habrían promovido la inversión productiva, en vez de la lentitud que de hecho experimentó la economía. En contraposición con McNally, concluye que las tasas de ganancia y «la economía nunca se recuperaron plenamente del deterioro de los años setenta» (p. 24).

Es aquí donde el estrecho enfoque de Kliman, en cuanto a la información de Estados Unidos, pone en aprietos a su propio argumento. Según la misma lógica que aplica antes, las inversiones fijas en la economía china debe tener altas tasas de ganancia, dado que han explotado en los últimos treinta años. Afirma explicar esto por medio de un análisis de las ganancias reportadas por las corporaciones estadounidenses en sus inversiones extranjeras y que aun así se adhieren a su conclusión primordial, en el sentido de que las tasas de ganancia han descendido. El problema con esta perspectiva es doble: 1) las corporaciones multinacionales estadounidenses son notables por esconder sus ganancias en paraísos fiscales en el extranjero, lo que deja sin sentido cualquier análisis de las ganancias reportadas (Shaxson, 2011), y 2) el nuevo centro de acumulación del capital en China es de naturaleza global, es decir, mientras que el capital estadounidense invierte ahí, igualmente lo hacen el japonés, el taiwanés, el coreano y, por supuesto, el chino. Kliman argumenta que «los pilares centrales del éxito [de China]» son los siguientes: «trabajo alienado, condiciones de explotación intensiva, desempleo masivo, represión y sueldos al nivel de pobreza» (p. 190). Aunque esto suena a pesadilla para los trabajadores, aparentemente es un sueño hecho realidad para el capital, como se evidencia en la enorme cantidad invertida que ha sido atraída hacia China. La atracción la constituyen las altas tasas de ganancia.

Tras contender con el argumento de McNally, de que las tasas de ganancia se elevaron durante el periodo neoliberal, Kliman lanza su fuego hacia Foster y Magdoff y lo que él llama la «alternativa del subconsumista» (por ejemplo, en cierto momento compara la escuela de Monthly Review con un «culto religioso»). Aunque está de acuerdo con Foster y Magdoff en que la expansión de la deuda animó artificialmente la rentabilidad y el crecimiento, lo que derivó en repetidas burbujas y caídas financieras durante la era neoliberal, rechaza el 
supuesto de que los salarios reales se hayan estancado durante ese periodo. En cambio, afirma que «los trabajadores estadounidenses reciben una paga más alta en la actualidad, en términos ajustados para la inflación, de la que recibían hace apenas unas pocas décadas», si se incluye la compensación total (p. 12). Mientras que «los sueldos y salarios en sentido estricto no han aumentado notablemente» (énfasis en el original), la compensación total, como parte del ingreso nacional, no ha decaído debido a que el patrón proveyó atención a la salud y al retiro y el Estado financió la seguridad social y el Medicare (p. 124). Los salarios no fueron redistribuidos según las ganancias, sino de «los salarios respecto a otras formas de compensación de los empleados» (p. 124). Con el objeto de argumentar que las ganancias no han aumentado, Kliman añade el argumento de apoyo de que mientras los salarios se han estancado, la compensación total no lo ha hecho $y$, por ende, los salarios bajos no han aumentado la tasa de ganancia. Pero el fundamento de ese argumento descansa sobre arena, ya que no sólo están bajo ataques esos programas de los patrones y del gobierno, sino que la carga de estos programas se ha pasado a los hombros de los trabajadores por medio de planes de pensiones de $401 \mathrm{~K}$, deducibles más altos para los seguros médicos y co-pagos e impuestos regresivos sobre la nómina.

Además, Foster y Magdoff utilizan la evidencia del estancamiento de los salarios reales para afirmar que la demanda efectiva de los trabajadores se ha incrementado únicamente a través de la ampliación de la deuda de los hogares, incluyendo los beneficios de atención a la salud y de pensión que no afectarían de manera medible el actual poder adquisitivo, así que incluirlos no tiene sentido. Si los salarios reales y la inversión productiva se han estancado en Estados Unidos, entonces podría ser un indicio de que el capital excedente se invirtió en la expansión de la producción en China (como argumenta McNally) o en el sector financiero para la especulación (como argumentan Foster y Magdoff) o en ambas cosas. La naturaleza dialéctica del desarrollo desigual del capitalismo sugeriría que las tasas de ganancia en declive del sector corporativo estadounidense trasladarían la inversión hacia donde las ganancias fueran mayores, sea por medio de la producción en China o un instrumento financiero de especulación. 
Aun cuando Kliman argumenta que la «intervención estatal permanente» desde la Gran Depresión ha salvado al capitalismo de su propio ser, pero al mismo tiempo ha evitado la destrucción del capital necesaria para reiniciar el proceso de acumulación, trata a todas las intervenciones del Estado como iguales, como si la seguridad social y el seguro de desempleo fueran lo mismo que el programa de aligeramiento de los recursos en problemas y la descarga cuantitativa. Pierde de vista la naturaleza de clase de estas intervenciones estatales. Además, mientras que la Gran Depresión destruyó capital, se requirió de creación de demanda por medio de la legalización de la sindicalización, el Estado de bienestar y el gasto militar para restaurar la rentabilidad. Cuando la recuperación del capital alemán y del capital japonés generó las condiciones de una crisis de sobreproducción, la clase capitalista no se puso a «resolverla» por medio de la creación de demanda, sino a través de una reorientación de la intervención del Estado para aumentar la tasa de explotación al atacar a los sindicatos y recortar los programas sociales. Por otra parte, el desplazamiento de la crisis de sobreproducción hacia el tercer mundo por medio de la imposición del neoliberalismo destruyó capital en el Sur global. De hecho, la serie de crisis financieras que ha diezmado la economía global desde entonces representa la destrucción de capital por medios financieros (Wade y Veneroso, 1998). Si no haber logrado destruir suficiente capital o reducir los sueldos sociales derivó en que no se lograra restaurar la rentabilidad, como afirma Kliman, entonces ello ciertamente no es por falta de intentos.

\section{TABBः FINANCIARIZACIÓN}

Mientras que Kliman se centra en el fracaso de la producción, Tabb se centra en el éxito de la financiarización. Mientras que Kliman entra en los detalles de la «interpretación del sistema temporal único» para explicar su medida de las tasas de ganancia, Tabb ingresa en el sistema bancario de las sombras, los fondos de doble garantía (bedge funds), la equidad privada y los derivados de 
ventanilla, los intercambios en la cartera vencida, los vehículos especiales de inversión y similares para explicar la financiarización $-y$ lo hace con gran claridad-. En el prefacio, Tabb dice que presentó el libro con el título Financialization: The Appropriations of Finance and the Restructuring of Capitalism in Our Time; como el título original era demasiado complejo, los editores deberían haberse quedado con «financiarización», ya que es el mejor libro disponible sobre el tema.

Tabb basa su análisis de la financiarización en el marco de las estructuras sociales de acumulación, la tendencia al estancamiento del capital monopólico (Foster y Magdoff, 2009) y la caída de la hegemonía estadounidense (Arrighi, 2007). Aunque este amplio análisis teórico está bien argumentado y es informativo, el libro es aún mejor cuando Tabb explica y analiza con claridad la gran cantidad de instrumentos e instituciones financieras que componen el capital financiero en la actualidad. En consecuencia, el libro sirve como una útil introducción para cualquier científico social, que suele tener dificultades para entender la diferencia entre una obligación colateral de deuda y un intercambio de cartera vencida.

Estos temas son cada vez más relevantes para una comprensión de las dinámicas del capitalismo en su actual etapa de desarrollo, lo que Foster llama la «edad del capital de las finanzas monopólicas» (2010). Pero dada la monopolización del capital por las finanzas, sería más exacto llamarla, simplemente, la «edad del capital financiero». Como se describe arriba, el capital financiero ha desempeñado un papel para resolver el problema de la realización por medio de la expansión de la deuda, abriendo nuevas oportunidades de inversión a través de la innovación financiera y la destrucción del capital por medio de las crisis financieras. Este último papel tiene especial importancia dentro del contexto del argumento de Kliman en el sentido de que el neoliberalismo no destruyó tanto capital como la Gran Depresión y la Segunda Guerra Mundial para reiniciar el proceso de acumulación. Según David Harvey, es ése precisamente el papel de las crisis financieras en serie en la época neoliberal: generan «amplios campos para la absorción de los capitales excedentes» a través de la «liberación 
de recursos de bajo costo» y proporcionar un «medio para visitar los costos de la devaluación de los capitales excedentes en los territorios y poblaciones más débiles y más vulnerables» (Harvey, 2003: 185). De tal modo, mientras que los altibajos de las burbujas y las crisis especulativas se convierten en desastre social para la mayoría de los trabajadores, las crisis destruyen financieramente al capital y abren nuevas oportunidades de inversión para el capital financiero.

Además, las intervenciones del Estado bajo la forma de rescates a los bancos no abordan el estancamiento subyacente de la producción sino que refuerzan el dominio del capital financiero a medida que se concentra más y se torna en un motor más significativo del crecimiento. En la Gran Depresión, el Estado intervino en apoyo de los trabajadores por medio de programas de obras públicas, seguros de desempleo y seguridad social, con el objeto de «salvar al capitalismo de sí mismo» (Kliman, 185). En la actual crisis, el Estado intervino para apoyar al capital financiero con el objeto de salvar al capitalismo de sí mismo.

La intervención del Estado bajo el neoliberalismo no fue retirada sino reorientada para servir a las necesidades del capital financiero. En Myths of Neoliberal Deregulation, Leo Panitch y Martijn Konings describieron esta transformación como sigue:

El papel altamente proactivo de Washington para contener las crisis financieras nacionales e internacionales desde los años ochenta en delante fue quizá la demostración más concreta de que el supuesto retiro de los Estados de los mercados constituía una ilusión ideológica. La financiarización aumentó el papel de Estados Unidos, tanto directa como multilateralmente, incluso amplió el espacio estratégico de maniobra disponible para el capital (2009: 72).

Haciendo uso de este «espacio estratégico de maniobra», el capital financiero infla burbujas especulativas y luego usa las inevitables crisis financieras para devaluar al capital, de modo que los recursos pueden «ser comprados 
a precios de remate y la rentabilidad es reciclada de nuevo hacia la circulación» (Harvey, 2003: 150). Las crisis especulativas constituyen el modo de acumulación bajo el capital financiero, ya que han «surgido como un medio primordial por el cual el capitalismo genera perpetuamente su propio "otro" con el objeto de alimentarse de él» (Harvey, 2003: 151). Adicionalmente, es poco probable que terminen pronto estos altibajos de burbujas especulativas y crisis financieras del capital financiero. En 2010, Simon Johnson, quien fuera economista en jefe del Fondo Monetario Internacional, argumentó que, en la crisis actual, «el sector financiero estadounidense recibió un rescate incondicional $-y$ no enfrenta ahora ningún tipo de nueva regulación significativa-. Nos disponemos, sin duda, a otra explosión basada en una toma excesiva e imprudente de riesgos en el corazón del sistema financiero mundial. Esto sólo puede acabar de un modo: mal» (2010). Dado el papel central que seguirá desempeñando el capital financiero en esta etapa del capitalismo, el libro de Tabb sobre la financiarización no podría ser más importante u oportuno.

\section{Conclusión}

El argumento de Foster y Magdoff en el sentido de que el capitalismo monopólico se estancó desde los años setenta no percibe el dinámico surgimiento de un nuevo centro de acumulación en China. El argumento de McNally de que el surgimiento de China representó una expansión neoliberal pierde de vista la contracción neoliberal en la mayor parte del resto del tercer mundo bajo los PAEs del FMI. El argumento de Kliman de que la intervención del Estado evitó la destrucción del capital para reiniciar el proceso de acumulación deja de lado la transformación de este proceso hacia el capital financiero. El enfoque de Tabb sobre la financiarización no percibe el papel del capital financiero para superar «la verdadera barrera a la producción capitalista» del capital mismo al destruir al capital. Es decir, aunque individualmente estos libros dejan de lado la naturaleza dialéctica del desarrollo desigual del capitalismo, tomados 
en conjunto la iluminan. El estancamiento y la expansión, la sobreproducción y la financiarización coexisten todos bajo el capitalismo en una interminable «danza de la dialéctica» (Ollman, 2003).

\section{Referencias}

Arrighi, Giovanni (2007), Adam Smith in Beijing: Lineages of the TwentyFirst Century, Nueva York, Verso.

Baker, Dean (2009), Plunder and Blunder: The Rise and Fall of the Bubble Economy, Nueva York, Berrett-Koehler Publishers.

Brenner, Robert (2002), The Boom and the Bubble: The us in the World Economy, Nueva York, Verso.

Foster, John Bellamy (2010), «The Age of Monopoly-Finance Capital», Montbly Review, vol. 61, núm. 9.

Foster, John Bellamy y Hannah Holleman (2010), «The Financial Power Elite», Monthly Review, vol. 62, núm. 1.

Freeman, Richard (2006), «The Great Doubling: the Challenge of the New Global Labor Market». Consultado en 〈http://emlab.berkeley.edu/ users/webfac/eichengreen/e183_sp07/great_doub.pdf .

Gowan, Peter (1999), The Global Gamble: Washington's Faustian Bid for World Dominance, Nueva York, Verso.

Harvey, David (2003), «The "New Imperialism”" Accumulation by Dispossession», en Leo Panitch y Colin Leys (editores), The Socialist Register 2004: The New Imperial Challenge, Londres, Merlin Press.

Harvey, David (2010), «The Crises of Capitalism», conferencia magistral dictada a la Royal Society for the Encouragement of Arts, Manufactures and Commerce (RSA), Londres (26 de abril). Consultado en 〈http:// www.thersa.org/events/vision/vision-videos/david-harvey-the-crises-of-capitalism>.

Johnson, Simon (2010), «Creating the Next Crisis», Project Syndicate (15 
de junio). Consultado en 〈http://www.project-syndicate.org/commentary/johnson9/English?.

Li, Minqi (2008), The Rise of China and the Demise of the Capitalist World Economy, Nueva York, Monthly Review Press.

MacEwan, Arthur (1991), Debt and Disorder: International Economic Instability and u.s. Imperial Decline, New York, Monthly Review Press.

Ollman, Bertell (2003), Dance of the Dialectic: Steps in Marx's Method, Champaign, University of Illinois Press.

Perkins, John (2008), The Secret History of the American Empire: The Truth About Economic Hit Men, Jackals, and How to Change the World, Nueva York, Dutton.

Panitch, Leo y Martijn Konings (2009), «Myths of Neoliberal Deregulation», New Left Review, núm. 57.

RAJAN, Raghuram (2010), «Let Them Eat Credit: How Inequality is at the Root of the Great Recession», The New Republic (27 de agosto).

Robinson, William I. (2008), Latin America and Global Capitalism: A Critical Globalization Perspective, Baltimore, Johns Hopkins University Press. Shaxson, Nicholas (2011), Treasure Islands: Uncovering the Damage of Offshore Banking and Tax Havens, Nueva York, Palgrave Macmillan.

WADE, Robert y Frank Veneroso (1998), «The Asian Crisis: The High Debt Model vs. The Wall Street-Treasury-Imf Complex», New Left Review, vol. I, núm. 228. 